\title{
Globalização, Informalidade e Regulação em Cidades Latino-Americanas *
}

\author{
Maria Lucia Refinetti Martins **
}

Resumo: 0 texto procura identificar e comparar, em algumas metrópoles latino-americanas, a manifestação de processos recentes e simultâneos: término de regimes militares autoritários, democratização e descentralização político-administrativa, reestruturação econômica e desregulamentação, ao lado de uma histórica e crescente irregularidade, informalidade e precarização do espaço urbano. Observam-se, nos diferentes países, similitudes dos impactos e das reações a esses processos, particularmente na esfera local - municipal e metropolitana. A partir desse quadro, reflete sobre identidades e sobre os padrões urbano-ambientais presentes nessas cidades.

Palavras-chave: Metrópoles Latino-americanas, Estrutura Urbana, Legislação Urbanística e Ambiental, Assentamentos Informais.

Abstract: This text intends to identify and compare, in some Latin American metropolises, the occurrence of recent and simultaneous processes, such as: the end of military authoritarian political regimes, democratization, political and administrative decentralization, economical restructuring and deregulation, together with an historical and growing irregularity, informality and precarization of urban space. Similarities of the impacts and the reactions to these processes are observed in this text, especially in what concerns the local sphere - municipal and metropolitan. From this panorama, the text presents a reflection about identities and urban-environmental standards that are present in these cities.

Keywords: Latin American Metropolises, Urban Structure, Urban and Environmental Law, Informal Settlements.

\footnotetext{
*Texto revisado e atualizado da versão apresentada no Seminário Colombo-Brasilero Legalidad Ilegalidad en la producción de la ciudad, Medellín 25-26 de novembro de 2004, publicada em espanhol nos respectivos anais.

** Doutora em Arquitetura e Urbanismo, Professora do Departamento de Projeto e Coordenadora do Laboratório de Habitação e Assentamentos Humanos da Faculdade de Arquitetura e Urbanismo da USP; Professora do Programa de PósGraduação em Integração da América Latina - PROLAM/USP. Anteriormente exerceu atividade de Planejador Urbano na Secretaria Municipal de Planejamento da PMSP e de Assessoria em Urbanismo a parlamentares na Câmara Municipal de São Paulo e Assembléia Legislativa. E-mail: malurm@usp.br. Recebido em 05/11/05 e aceito em 22/12/05.
} 
O texto apresenta um trabalho de Identificação e comparação da manifestação, em algumas metrópoles latino-americanas, de processos que, nas últimas décadas, vêm ocorrendo simultaneamente, ainda que vinculados a origens e razóes diversas. São, de um lado, os processos de: Globalização e Reestruturação Econômica, que vêm de fora para dentro em cada país e, de outro, processos internos de Democratização e Descentralização Político-Administrativa implementadas a partir do término de regimes militares autoritários. Visualizam-se nos diferentes países latino-americanos similitudes e simultaneidade na ocorrência desses processos e de seus respectivos impactos na esfera local - municipal e metropolitana. Interessa trabalhar sobre essas metrópoles com uma perspectiva latino-americana, tanto na busca de identidades e de processos comuns, quanto na busca de padróes e referências para construção de políticas públicas que enfrentem sua realidade de centros de um capitalismo periférico.

\section{Um perfil peculiar}

A América Latina e suas metrópoles no final do século XX apresentam algumas condiçóes semelhantes e convergências:

No conjunto dos países desencadeia-se um processo de Descentralização que confere maior autonomia e fortalecimento financeiro dos Municípios, com transferência de competências do governo central para o local.

Por outro lado, as reestruturaçóes associadas à globalização configuram um quadro em que grandes conglomerados econômicos presentes na América Latina, que têm as sedes de seus comandos para a regiáo nas principais metrópoles, requerem condiçóes de funcionalidade urbana de superior qualidade, o que se constitui à custa de concentração de investimentos em determinadas áreas das cidades ao lado de reduzida oferta de serviços públicos onde não há mercado.

Verifica-se a ampliação da informalidade na atividade econômica, no mercado de trabalho e nos assentamentos urbanos. A grande parte dos territórios urbanos é constituída por assentamentos irregulares e precários - um amplo espectro de urbanismo náo oficial, que convive com todo tipo de "informalidade".

Se ao primeiro movimento - transferência de competências do governo central para esferas locais podemos atribuir um caráter de inovação - no sentido de mudança, os demais: concentração de infraestrutura de qualidade 
superior em determinados pontos nas metrópoles e a presença de assentamentos precários, refletem a permanência de uma condição que apenas se aprofunda, por razóes internas e externas.

Globalização e reestruturação econômica apenas reforçam e amplificam tradicionais tendências de concentração e segregação. Observar esses processos na escala do espaço urbano implica em olhar para a cidade enquanto objeto material, enquanto forma, buscando visualizar tais processos a partir de suas manifestaçóes físico-espaciais. Trata portanto de identificar as demandas de espaço que esses processos requerem e engendram - uma abordagem da cidade relacionando Espaço Urbano e Economia. No entanto é necessário considerar, que se tais processos vêm ampliando a concentraçáo econômica e territorial, as cidades, em si, também produzem concentração e segregação, esta de natureza territorial, onde não só a propriedade mas seu usufruto têm valor. Assim, impossível estudar a cidade sem situá-la entre esses dois contextos: a atividade econômica e o lugar.

Nesses termos, é necessário observar-se o espaço urbano segundo duas óticas que se sobrepóe e se somam, apesar de aparentemente antagônicas ou conceitualmente contraditórias: a) o rebatimento no espaço físico das cidades dos processos associados às transformaçóes capitalistas recentes; b) a associação da organização das cidades e de seus bairros mais à estrutura de classes e poder e à tradiçáo patrimonialista do que às mudanças no capitalismo.

Há que se admitir, conforme Villaça (1998) observa para as metrópoles brasileiras, que sua estrutura urbana se explica muito mais pela estrutura e funcionamento tradicional da sociedade brasileira enquanto distribuição de renda e poder do que pelas transformaçóes do capitalismo no país e no mundo. Segundo ele, nas metrópoles brasileiras, são os bairros residenciais das classes de renda alta que efetivamente desenham a cidade, inclusive deslocando o próprio centro. Para esse autor, tal processo não é uma particularidade das décadas recentes e de uma eventual atuação do capital imobiliário ou das leis de zoneamento contemporâneo, mas vem se constituindo no Brasil há mais de um século. Desde meados do século XIX as classes acima da média vêm tendendo a se segregar crescentemente em uma única região geral da metrópole (a zona sul no Rio e Belo Horizonte, o quadrante sudoeste em Sáo Paulo) e, em seu deslocamento espacial, tendem a fazer com que o centro principal cresça - contínua ou descontinuamente - na sua mesma direção. 


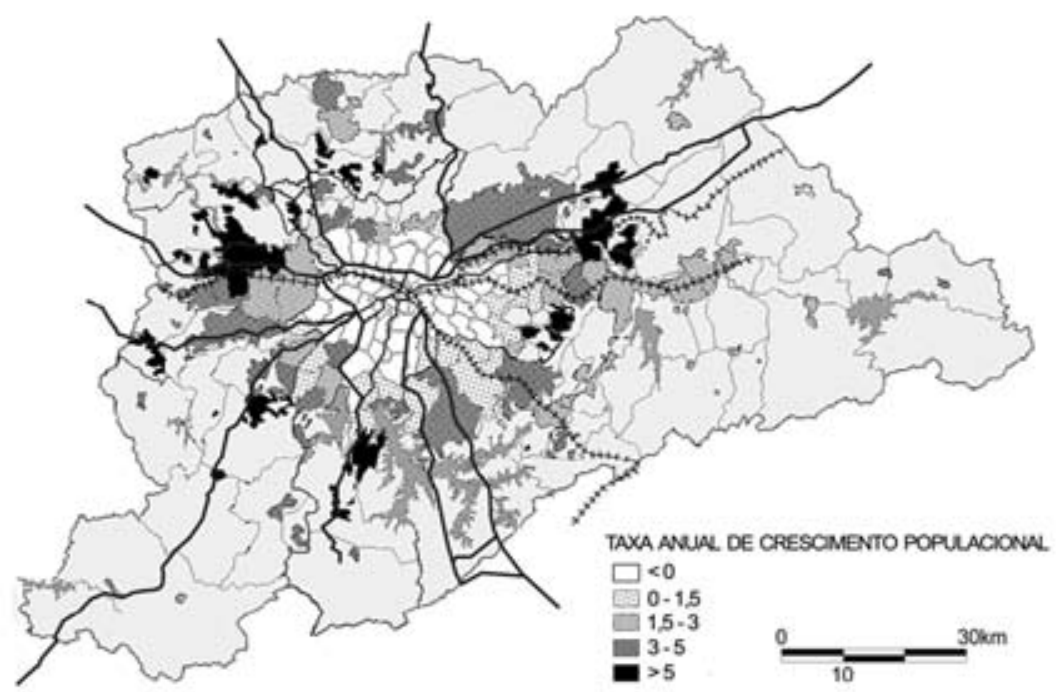

FIG 1.1

FIG 1.2

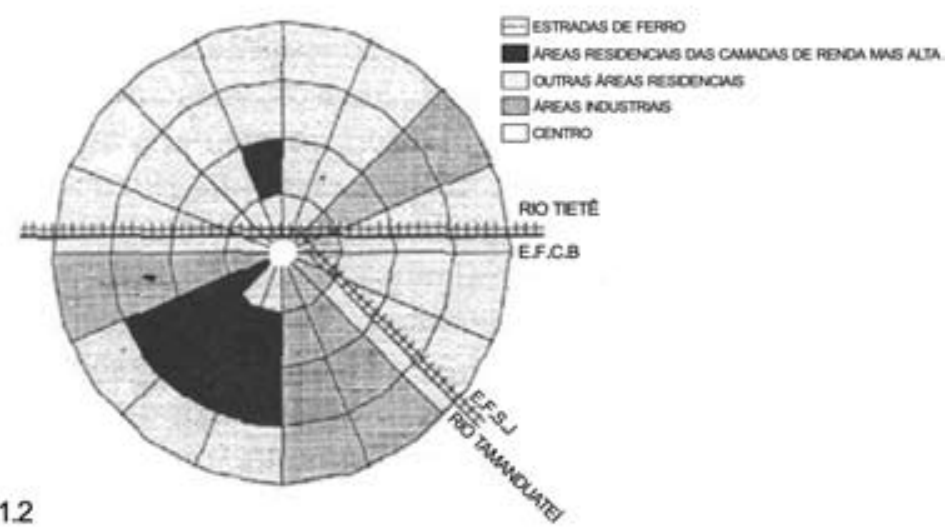

Figura 1 - 1.1. Região Metropolitana de São Paulo - área urbanizada e taxas de crescimento populacional 1991-1996. ${ }^{1}$; 1.2. Sáo Paulo - estrutura espacial da metrópole: concentração de "bolsôes de qualidade" em determinadas direçóes. FONTE: VILLAÇA, 1998, p. 115.

${ }^{1}$ FONTE: mapas base CESAD/FAUUSP e EMPLASA. Dados estatísticos IBGE. Colaboração e desenho: Luciana Nicolau Ferrara e Ana Paula Gonçalves Pereira 
Esse mesmo quadro de "caminhamento do Centro" e de concentração de investimentos públicos e privados em determinadas direçóes nas cidades, se observa presentemente em diversas metrópoles latino-americanas, onde, além disso, ocorre também, como em São Paulo, a perda de população nas áreas centrais mais equipadas, e um maior crescimento - expansão horizontal e adensamento, nas áreas mais precárias, ambientalmente mais frágeis e sem infra-estrutura, conforme apontam trabalhos apresentados nos encontros da REDII. ${ }^{2}$

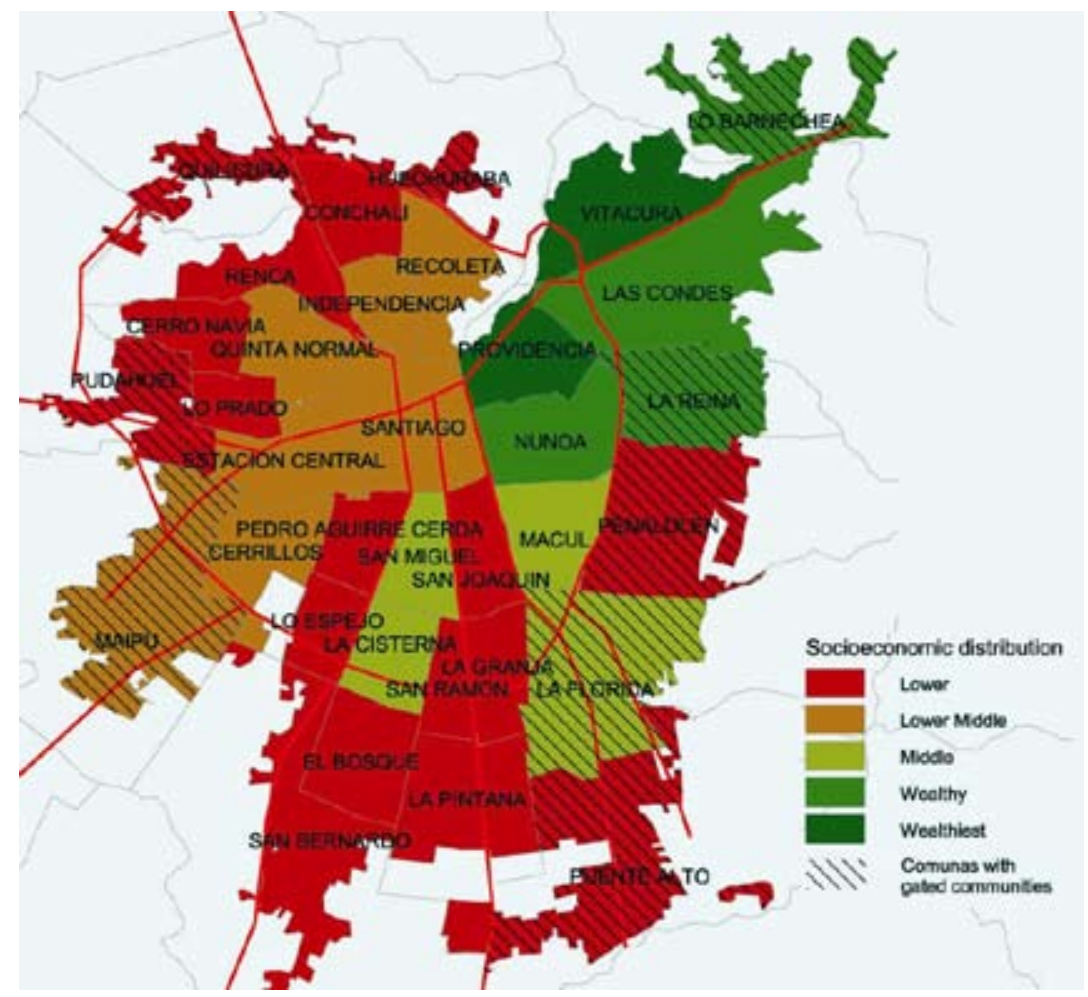

Figura 2 - Santiago de Chile - Distribución socioeconómica 2002 FONTE: ARCE, 2004.

- Concentración de grupos de altos ingresos en la zona oriente.

- Concentración de grupos de bajos ingresos en la zona sur o nor poniente.

- Aparición de barrios cerrados en zonas pobres gracias a la llegada de grupos sociales de mayores ingresos.

${ }^{2}$ Toluca, Mx (1999); Rosário, Ar (2000); Camaguey, Cuba (2000); Rio de Janeiro, Br (2004). 


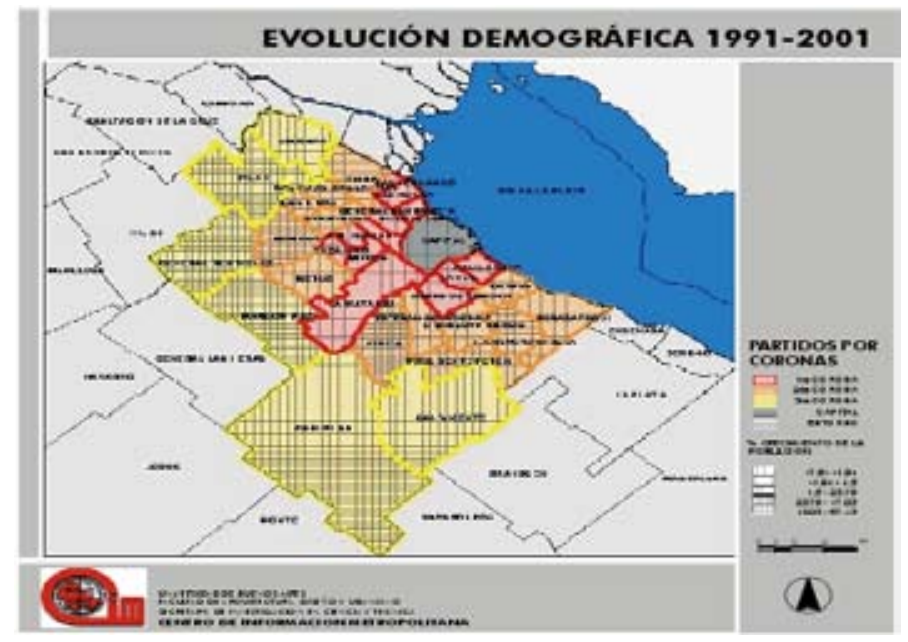

Figura 3 - Buenos Aires - Av Rivadavia divide o norte rico e equipado do sul pobre e com áreas abandonadas

FONTE: KOPPMAN, 2004.

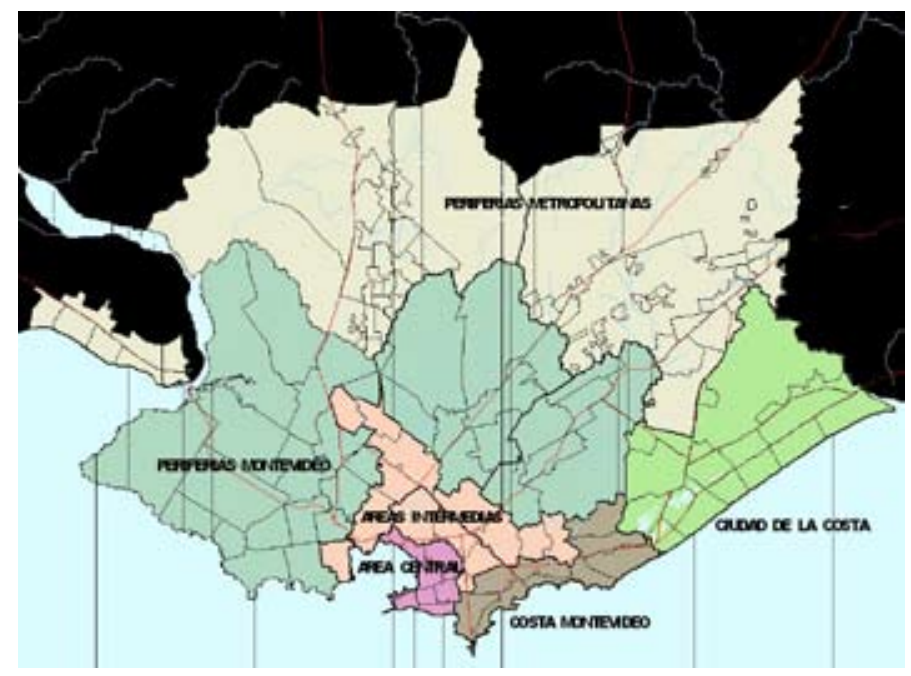

Figura 4 - Montevideo - Los sectores de bajos ingresos procuran el acceso a la vivienda mediante la autoconstrucción periférica y los asentamientos irregulares, mientras que los sectores de ingresos medios - altos tienden a migrar hacia los espacios urbanos y periurbanos más calificados, principalmente en la franja de la costa este

FONTE: LOMBARDI; BERVEJILLO, 1999. 


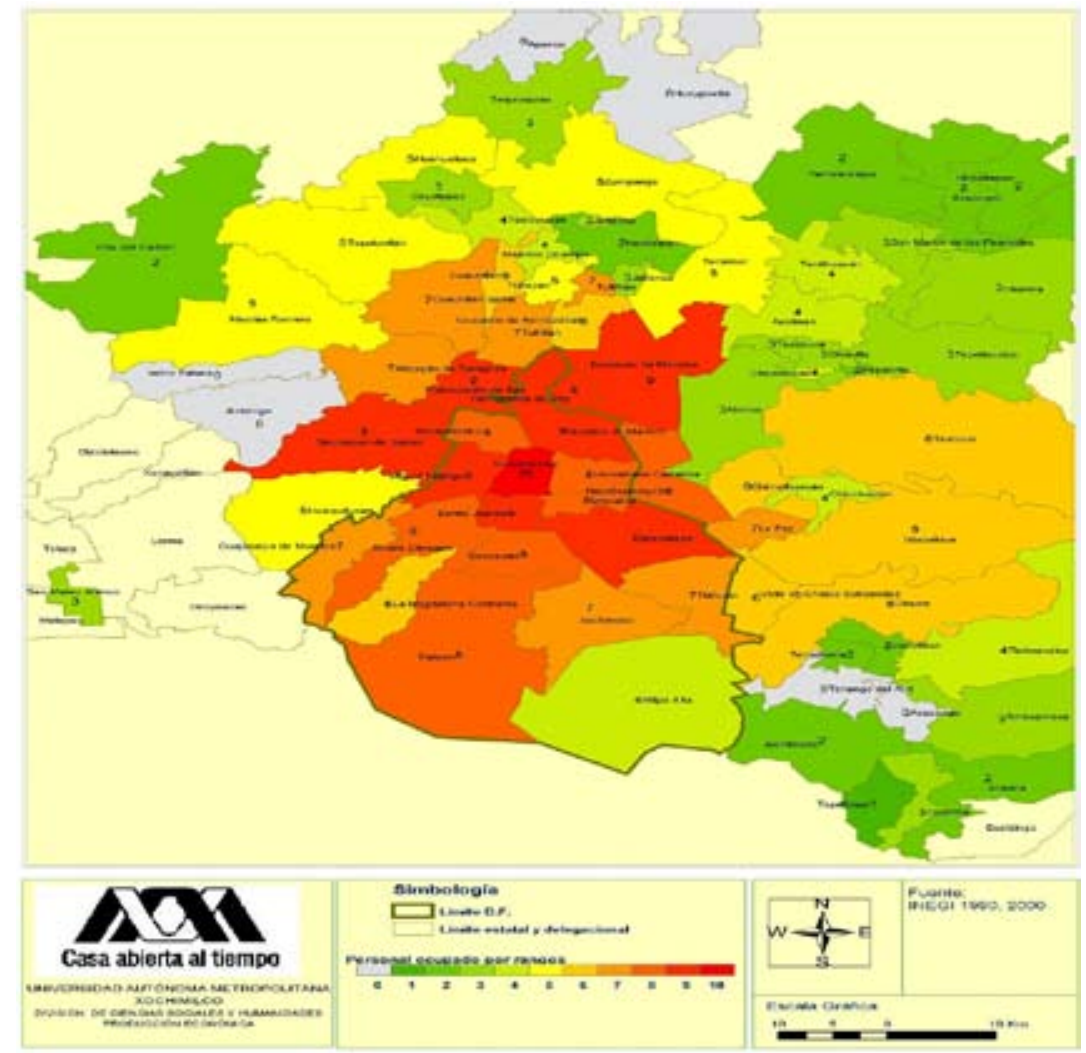

Figura 5 - Cidade do México - La riqueza se encuentra sobre todo en el poniente y en el sur; En las partes mas globalizadas la diferenciación socio-espacial es mas pronunciada FONTE: VILAREAL, 2004.

Nesse quadro de estrutura do espaço, que não é decorrente, mas que se intensifica como conseqüência da globalização e do ajuste econômico, a morfologia metropolitana é afetada também pela criação de novos "artefatos" urbanos - todos aqueles que respondem às demandas da nova economia: os edifícios inteligentes, as redes de fibra ótica, que atendem à parcela superior dessa economia. Correspondentemente a eles, na outra extremidade do processo, surge a "venda de lajes" - verticalização do espaço informal. A laje, cobertura plana de moradias auto-construídas é o espaço virtual criado sobre espaços informais e irregulares. É o artefato que expressa a outra face da nova economia: precarização do emprego e da renda e, enquanto política pública 
de acesso à moradia, muito pouco investimento e oferta por parte do Estado, ao lado de uma normativa restritiva - que, com o bom propósito de impedir a oferta no mercado de uma forma urbana precária - lotes sem qualidade e sem infra-estrutura, de baixo custo, acaba apenas, não por evitar a condição de precariedade, mas por manter os assentamentos com essas características indefinidamente na ilegalidade.

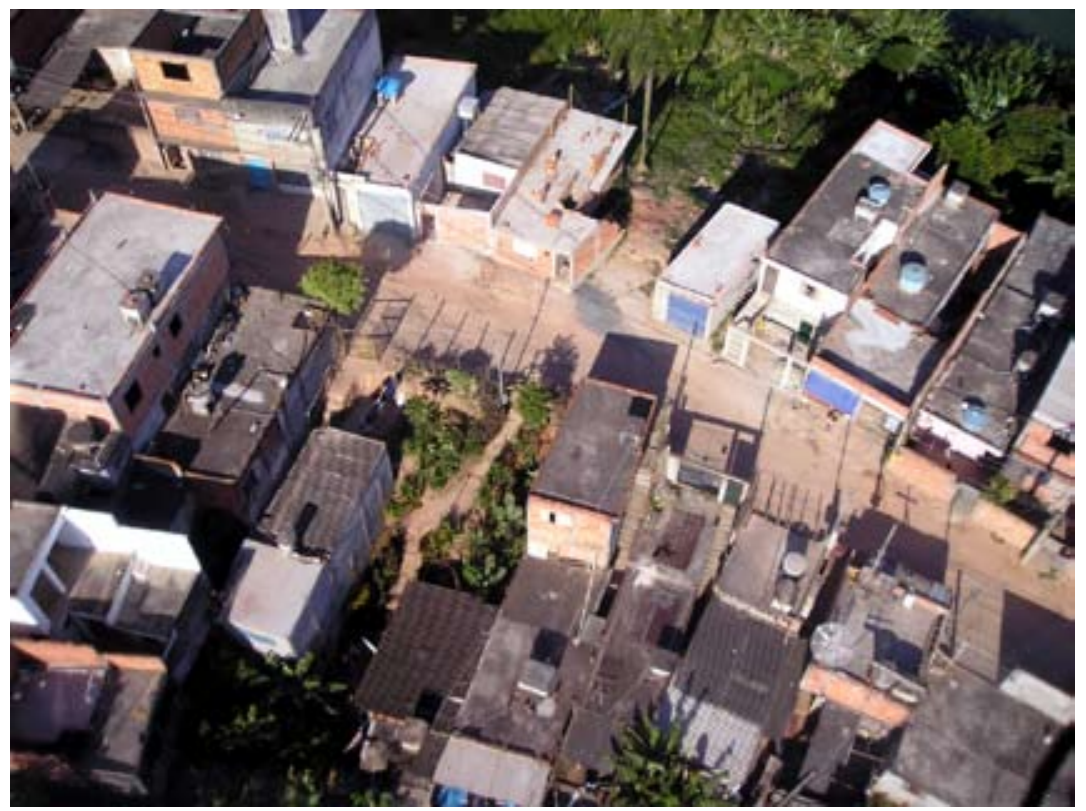

Figura 6 - São Paulo. As lajes e a verticalizaçáo do espaço informal FONTE: Fotografia da autora

A maior parte do crescimento populacional é periférico; não nos moldes do subúrbio - acesso a mais espaço, mas do adensamento dos espaços precários já ocupados. A conjugação da precarização do trabalho e da renda, associada ao modelo econômico e às restriçóes urbanísticas e ambientais nas bordas da área urbanizada, mais o limite natural das distâncias ao centro, levam a um progressivo adensamento do espaço edificado e do congestionamento das unidades habitacionais - $65 \%$ do déficit brasileiro de habitação é representado pela coabitação de famílias no mesmo domicílio. ${ }^{3}$

${ }^{3}$ Fundação João Pinheiro/ Centro de Estatísticas e Informações. Déficit Habitacional no Brasil 2000. 


\section{A formação da irregularidade}

Na maior parte da América Latina, nos primórdios da industrialização, com a reduzida capacidade do Estado de promoçáo e gestáo de políticas públicas voltadas ao assentamento humano e prioridade dos recursos públicos dada à implantação da infraestrutura para a Produção, o assentamento dos grandes contingentes de populaçáo que afluíam à cidade a cada dia, se deu majoritariamente pela auto-construçáo de moradias em arruamentos na periferia das cidades, de baixíssima qualidade, sem infraestrutura, com lotes comercializados a baixo custo e a prazo.

Sem qualquer restrição ambiental, funcional, de qualidade ou estética, esse processo, marca desde seu início uma ocupaçáo territorial predatória, contínua, sem a mínima reserva de áreas públicas e em condiçôes técnicas que na grande maioria das vezes desencadeou situaçōes de erosão de difícil controle.

Esse processo não deixou de ter continuidade, nos anos mais recentes, sob formas talvez um pouco diferenciadas, apesar da redução das taxas de crescimento e do desenvolvimento de instrumentos de controle. A principal expansão urbana continua se dando de modo precário, generalizando o designado "assentamento informal".

No Brasil, como na Argentina e pode-se concluir, na maioria das metrópoles da região, foi fora dos núcleos centrais mas dentro das regióes metropolitanas que ocorreu o maior crescimento de população, com a conseqüente intensificação dos processos de periurbanização precária, ao lado da implantação segregada dos mais diversos tipos de condomínios e loteamentos fechados, que abrigam populaçóes de renda mais alta.

No Brasil, do final dos anos 40 até meados da década de 70 o país teve seu mais intenso ritmo de urbanização, num quadro em que o censo de 1970 crava a marca da superação da população rural pela urbana, que atinge, entáo, $55,9 \%$ do total da populaçáo do país. Nesses trinta anos mais de 50 milhóes de habitantes deslocaram-se do campo para a cidade. Essa passagem se deu sob a forma de expansáo periférica e precária das cidades. Apenas ao longo da década de 70 tem início uma legislação com alguma exigência de condiçóes de salubridade e estabilidade do terreno, infra-estrutura e espaços públicos. A legislaçáo paulistana que impóe regras de qualidade aos loteamentos é de 1972; a legislação nacional sobre esse assunto é de 1979 - a Lei Federal $6766 / 79$. 
A existência da Lei ao lado da ausência de alternativa habitacional acessível a grandes parcelas de população pobre nas grandes cidades, particularmente nas duas últimas décadas, teve como conseqüência, a crescente ocupação irregular e informal.. Os loteamentos irregulares, as ocupaçóes informais e as favelas proliferam na franja urbana e nas áreas protegidas por lei (através de restrições ao uso, por razóes ambientais ou de segurança e insalubridade) - e consequentemente excluídas pelo mercado imobiliário.

Condição semelhante ocorreu em Buenos Aires, pois em 1977, durante o governo militar, a Província de Buenos Aires aprovou o Decreto-Ley No 8912, sobre uso do solo, proibindo os loteamentos sem obras de infra-estrutura básica. Essa legislação se articula com a implementação, na cidade de Buenos Aires da erradicação de favelas ("villas") e construção de autopistas, bem como uma política de aluguéis.

A partir dos anos setenta, "las formas que adopta la producción de la ciudad para la población de bajos ingresos, se diversifican; surgen formas no usuales aún en Argentina, pero comunes en otros paises latinoamericanos, como los loteos irregulares y clandestinos, muchos de ellos en terrenos no aptos para la localización residencial (inundables, cercanos a basurales, etc.)".

É o mesmo processo que ocorre em São Paulo, no período que se segue à aprovaçáo da Lei 6766 de 1976, que dispóe sobre aspectos semelhantes ao estabelecido no Decreto-Ley No 8912.

A desconsideração dos processos econômicos na formulação das regulamentaçóes e instrumentos leva ainda, no caso brasileiro - como outras cidades da região, com perfil social, político e cultural semelhantes, onde controle/fiscalização/sansão são sempre precários, a distorçôes que causam efeitos exatamente opostos aos pretendidos. É o caso, por exemplo, em São Paulo, da legislação referente à proteção dos mananciais, para onde a Lei Estadual 898/75 (Proteção dos Mananciais) estabelece controles e restriçóes de caráter ambiental, além das condiçóes urbanísticas já definidas pela Lei Federal 6766/79 (sobre condiçốes de abertura de loteamentos). A primeira, ao restringir muito o índice de ocupação das áreas às margens das represas com intuito de garantir sua preservação, levou a que a área fosse sendo tanto vendida a grupos populares, que a ocuparam de modo informal, quanto diretamente invadida e ocupada em condiçóes precárias e sem qualquer

\footnotetext{
${ }^{4}$ Nora Clishevsky. Regulación del habitat informal: un instrumento de política social? VIII Seminário REDII. Rio de Janeiro 2004.
} 
infra-estrutura. A segunda, estabelece condiçôes urbanísticas mais exigentes e adequadas para aprovaçáo de loteamentos. Isso acaba significando, no entanto, maior custo para produçáo do lote, que acaba sendo transferido do empreendedor ao comprador. Ainda que a Lei, para sua época e para a maioria das cidades pequenas e médias tenha representado uma conquista, nas metrópoles gerou processos adversos. Considerando-se as limitações de renda de grande parte da população, não será por coincidência que na década de 80 evidencia-se alteração da dinâmica espacial das metrópoles brasileiras: o crescimento extensivo, com a incorporação de novas áreas periféricas através da abertura e oferta de loteamentos populares, sofre visível retração. Paralelamente, ocorre uma explosão de cortiços e favelas.

Compreender a materialidade real dessa cidade, seus padróes e parâmetros físicos e legais é fundamental e urgente: apesar de a totalidade das cidades médias e grandes contarem com sistemas de planejamento e regulação urbanística, a maior parte de seus territórios é constituída por assentamentos irregulares e precários. Esse amplo quadro de urbanismo não oficial antecede a globalização, mas se intensifica e se agudiza com ela.

As sucessivas legislaçóes que buscam evitar precariedades urbanas via Lei, dissociadas de alternativas de oferta ampla de moradias, levam apenas a uma transformação do problema: dos loteamentos sem infra-estrutura à favela, ao adensamento habitacional e à cohabitação

Em São Paulo, a situação hoje é de uma extensa área de loteamentos irregulares, sendo grande parte deles em áreas de risco ou que comprometem os mananciais urbanos. A situação aí se torna ainda mais grave pois nesses casos, pelo fato de estarem em locais protegidos, é proibida a instalação de infraestrutura de saneamento, particularmente o tratamento local de esgoto. Há da ordem de um milhão e meio de pessoas nessas condiçóes no entorno dos mananciais da cidade de Sáo Paulo (Represas Guarapiranga e Billings), ao que se soma toda a quantidade de moradores em margens de córregos, legalmente áreas protegidas, não edificandi. Do ponto de vista jurídico são irregularizáveis segundo a legislação existente; do ponto de vista social representam a única alternativa de moradia de enorme parcela da população.

Quebrar esse círculo de insensatez implica em reverter procedimentos de trabalho e de proposição de regulamentaçóes, viabilizando efetiva correspondência entre legislação e condição concreta. Ora, nossa tradição 
quanto à regulamentação urbanística tem sido a da aprovação de Lei / pouca efetividade da Lei (irregularidades) / anistia e elaboração de Lei mais rigorosa, que estimula o descumprimento e a irregularidade, nova anistia ou a permanência na insegurança da irregularidade, e assim indefinidamente. Não é exagero avaliar-se que a grande maioria dos arruamentos e regulares em São Paulo, o são, não por terem sido feitos nos moldes da lei então vigente, mas por força de anistias ou formas de regularização. Aqueles que tiveram sua aprovação estritamente dentro da Lei, previamente à implantação, são inequívocas exceçóes.

A Lei 6766/79 está em revisão no congresso Nacional. Várias tem sido as contribuiçóes da sociedade para seu aperfeiçoamento. Espera-se que o Congresso tenha a sensibilidade de não repetir nessa nova Lei os erros que a realidade das periferias metropolitanas enfaticamente já demonstrou.

\section{A natureza da irregularidade}

Nas condiçóes latino-americanas, de reduzida correspondência entre a legislação urbanística e a realidade, num contexto de forte exclusão social, um desafio inicial é conceituar ou especificar melhor o conteúdo e natureza da expressão "informal" ou "irregular", particularmente no que se refere aos assentamentos de populaçóes de baixa renda. Adequado ou não, só é irregular o que a legislação estabelece como tal. Aí se torna evidente o grande fosso entre o desejável (padróes estabelecidos nas leis) e a realidade urbana. $\mathrm{Na}$ maioria de nossas metrópoles - particularmente em sua parcela mais periférica, o irregular predomina em quantidade e extensão sobre o regular. Nessas condiçóes, o que se poderia chamar de regularidade ou de "padrão"?

As diversas formas de assentamentos de moradia urbana têm, por definição, o objetivo de acomodar a população na cidade. Nesses termos, regularidade corresponderia a atender a um padrão, que fosse o mínimo, social e economicamente aceitável, que inclua salubridade e segurança, fundamentado na experiência concreta e na capacidade de provisáo pela sociedade, e não em modelos ou padróes estabelecidos em outras realidades, em outras sociedades. Padráo e necessidades variam ao longo do tempo. À medida que tecnologia e produção de bens se amplia, a noção de necessidade básica também. Como a distribuição de renda é muito desigual, com extremos, o parâmetro legal é hoje uma referência ambígua, inacessível à 
maioria, no que resulta excludente e discriminador.

Por outro lado, regular é o que está na Lei; é o que está de acordo com a legislação urbanística e ambiental. E o que está na Lei, é o que os legisladores entenderam por bem colocar, buscando determinados objetivos e estabelecendo sob a forma de artigos - os "Termos da Lei", os meios para atingi-los. Ocorre que nem sempre os meios levam aos objetivos pretendidos. É o que se observa, conforme indicado anteriormente, em relação à Regiāo Metropolitana de São Paulo. A legislação restritiva aplicada aos parcelamentos, associada à baixa renda de amplos setores da população e à ausência de outras alternativas para a habitaçáo popular, geraram um vasto espectro de soluçóes informais, improvisadas e irregulares, que o Estado se mostra francamente incapaz de equacionar. Nessas condiçóes, entendendo que o fundamento das leis urbanísticas e ambientais é regulamentar para que os assentamentos tenham condiçóes físicas e serviços adequados - para a família e para a comunidade (sem impactos negativos ou riscos para si e para o conjunto da cidade), o conceito de "razoabilidade" parece permitir que se coloque a questão: irregular é o que se afasta dos termos da Lei ou dos objetivos da Lei ? Uma Lei cuja aplicação, no quadro da realidade existente, incapaz de atingir seus padróes, acaba por induzir irregularidades, pode ser considerada legítima?

Um terceiro aspecto da idéia de "regularidade" refere-se à segurança da permanência da população na área em que vive. Refere-se a um tema social, que é a segurança da posse, mas fica normalmente associado à propriedade, e a propriedade à sua escrituração. Do ponto de vista da regularidade urbanística, a regularidade da propriedade e e seu registro só entram na questão porque toda a ordem urbanística tem início na comprovação da regularidade da propriedade: para dar início aos procedimentos de aprovaçáo de qualquer parcelamento ou loteamento é necessária a regularidade da propriedade.

Feitas essas consideraçóes, fica evidente que nem tudo que é irregular é precário. No entanto todos os assentamentos precários são irregulares. A irregularidade, nos assentamentos populares deve-se normalmente ao fato de não seguirem a regulamentação, contendo padróes muito abaixo dos exigidos por Lei: declividade maior do que a permitida, lotes menores do que a área mínima, falta de áreas públicas, falta de infra-estrutura. Novo círculo vicioso se estabelece: o assentamento é irregular por estar abaixo do padráo estabelecido em Lei - portanto, para tornar-se regular, é necessário investir recursos - 
desapropriaçóes, remoçóes e obras. No entanto, para obter financiamento é necessário que o assentamento seja regular: desde a propriedade da terra à aprovação do projeto e sua implantação. Conseqüentemente, se pereniza a irregularidade.

\section{Superar a irregularidade}

Em relação aos assentamentos precários e em desacordo com a Lei, os Operadores do Direito visam o exercício da Justiça, enquanto os Urbanistas visam a melhoria da qualidade ambiental. A sansão por meio de multa é inócua frente aos olhos do Urbanista, como ao Jurista é imprópria a qualificação ambiental fora da Lei. Nesses termos, o encaminhamento de investimentos, questóes técnicas e jurídicas têm necessariamente que andar juntos e de forma coerente e articulada.

Os conceitos e a prática do Direito Urbanístico e Ambiental exigem reconsideração. É da natureza do Direito assegurar direitos. No entanto, o Direito de um modo geral e particularmente o Direito Urbanístico e Ambiental é muitas vezes invocado como recurso para manutenção do status quo em detrimento de processos de transformação que justamente visem assegurar direitos. As transformaçóes, principalmente as urbanas, acabam sendo feitas informalmente ou ao arrepio da Lei.

Contrapondo-se a essa situação, novos Códigos visando promover e assegurar o Direito à Cidade surgiram no continente na última década: $\mathrm{O}$ Estatuto da Cidade, no Brasil (2001) e a Lei 388 (1997) na Colômbia. São Leis nacionais que buscam configurar o Direito à Cidade.

O Estatuto da Cidade introduz diversos instrumentos e alternativas, cuja aplicação, no entanto não pode ser aleatória ou generalizada. É necessária uma coordenação sinérgica de vários fatores - o projeto de regularização exige uma concepção integrada e articulada de: projeto urbanístico; tecnologia e projeto de infraestrutura, solução de regularização urbanística (adequação, revisão de Leis, enquadramento como ZEIS), solução de regularização da propriedade (compra e venda, desapropriação, usucapião, usucapião coletivo, concessão especial simples desmembramento da gleba em lotes), solução de financiamento das obras, solução de manutenção (condomínio, cooperativa, responsabilidade do poder público). 


\section{Construindo um olhar}

No processo de industrialização, sendo a indústria nascente significativamente urbana, o território da cidade passou a valorizar-se como suporte para as atividades, fossem elas a produção ou a reprodução social. De qualquer forma seu papel predominante permanece sendo o de estrutura física. Nessas condições é que se desenvolvem as regulamentaçóes urbanísticas, tendo por objetivo um controle sanitário e ambiental.

Esses controles surgiram então, com caráter restritivo. Num período desenvolvimentista e de efetivo crescimento, entendia-se que as restriçóes seriam capazes de orientar o adequado desenvolvimento urbano, sem prejudicar a atividade econômica.

Nas atuais circunstâncias em que a atividade imobiliária tanto quanto a valorização das localizaçóes representam parcela importante na movimentação econômica, as condiçóes urbanísticas representam parte do empreendimento. A produtividade e competividade dos empreendimentos deixam de ser definidos, conforme Santos (1999), devido apenas à estrutura interna de cada corporação e passam, também, a ser um atributo dos lugares.

Analisar processos econômicos que se realizam na cidade, de modo associado à produçáo do ambiente construído, bem como avaliar diretrizes urbanísticas e localização de equipamentos, como formas de transferência de renda é um caminho essencial para pensarmos o papel da cidade no novo contexto econômico e político.

Esse conjunto de condiçóes resulta numa notável valorização do espaço urbano equipado, particularmente nas grandes metrópoles e seus entornos. Dessa valorização decorre que o espaço urbano em si, e tudo que nele interfere - regulamentaçóes urbanísticas e obras públicas passam a ter importância econômica cada vez maior.

Reforçando esse quadro é bom lembrar que em praticamente todos os países, a missáo de promover e orientar o desenvolvimento econômico é primordialmente do governo central - Nacional, e tem, a partir de determinado momento, que varia do final dos anos 70 no Chile aos 90 no Brasil e na Argentina, priorizado como missão, manter a macroeconomia em ordem e cuidar para que o meio ambiente econômico seja confiável e atrativo ao mercado, mesmo que isso implique em juros sempre elevados, que restringem o crescimento econômico. 
Por outro lado, a nova economia reduz o emprego, particularmente o emprego estável e regular para as parcelas mais despreparadas e frágeis da população. Ao mesmo tempo, requer condiçóes de funcionalidade urbana de superior qualidade, o que vem se constituindo a custa de concentração de investimentos em determinadas áreas da cidade ao lado de reduzida oferta de serviços públicos onde não há mercado e em assentamentos populares ilegais.

Disso tudo resulta ser necessário que se tratem questóes territoriais e urbanísticas como disputa econômica e social e náo simplesmente como ordem e funcionalidade.

Por outro lado, se a discrepância de condiçôes urbanas edificadas, com "ilhas de eficiência" na cidade vem viabilizando nos anos recentes o funcionamento dos negócios e empresas da nova economia, as condições ambientais, que são indivisíveis começam a demonstrar seu limite, chegando a situações críticas que afetam não só a parcela excluída mas toda a comunidade - de pessoas físicas aos próprios negócios - como é o caso do limite da disponibilidade de água potável, da poluição dos mananciais e redução de sua carga abaixo dos níveis de segurança, das enchentes, da crise de energia elétrica, da proliferação de doenças como a dengue (no caso brasileiro), transmitida por vetores.

Enfrentar esses temas deixa de ser apenas uma questão de justiça social mas também de viabilidade de qualquer desenvolvimento. Nesse contexto, a formulação de Políticas Urbanas nas metrópoles de países periféricos, particularmente da América Latina exige repensar o Urbanismo: entre as demandas de funcionalidade do setor produtivo internacionalizado e o quadro de degradação sócio-ambiental das metrópoles, há o que designar por "eficiência" ?

No entanto a agências multilaterais e programas de cooperação induzem um pensamento sobre a cidade e uma leitura de seus problemas que, desconsiderando os contextos locais, procedem a:

Organização um acervo de boas práticas - que, enquanto forma de produção e utilização do conhecimento, no limite nada divergem dos modelos e padróes urbanísticos que ao longo da história temos transferido para nossas cidades, tantas vezes sem sequer uma transposição crítica;

Incorporaçáo de uma metodologia e priorização de questóes que dificilmente e só por acaso respondem a nossas efetivas necessidades;

Desenvolvimento de terminologia ambígua que incorpora com novo 
significado expressões da luta social, daí a constituição de um "espaço turvo" entre a descentralização vista como meio para a democratização e o enfraquecimento do Estado frente ao mercado; entre os anseios por autonomia do movimento popular e o projeto de redução do Estado e de sua desresponsabilização quanto a políticas sociais, dos neo-liberais.

É nesse contexto que o estudo e compreensão de nossas metrópoles com uma perspectiva latino-americana se mostra urgente e fundamental, para a formulação de instrumentos urbanísticos, padrões e regulamentação, mais realistas, universais e includentes. ${ }^{\mathbf{5}}$

\begin{abstract}
${ }^{5} \mathrm{O}$ presente texto advém de experiências e reflexões provenientes de três diferentes origens, num contexto em que cada qual a seu modo ajuda a compor os argumentos do tema:

A Red Iberoamericana de Investigadores sobre Globalización y Território - REDII que, desde 1994 reúne pesquisadores da América Latina, Portugal e Espanha com o objetivo de estabelecer uma instância de intercâmbio de pesquisas a respeito das consequêencias territoriais das transformações sociais e econômicas derivadas da crescente internacionalização do capital e da revolução técnico científica. Seu grupo temático: Globalización y Expansión Metropolitana vem procurando construir conhecimento e análises comparativas por meio de chamadas de trabalhos que busquem análise e interpretação dos conceitos de globalização e do tipo de interação globalização - metropolização, obsevando impactos em aspectos como: produção do espaço urbano, morfologia, base produtiva, condições de renda e qualidade de vida, estruturas institucionais de gestão metropolitana, formas participativas e estratégias de tomada de decisões.
\end{abstract}

O Programa de Pós-Graduação em Integração da América Latina - PROLAM, da Universidade de São Paulo, onde a disciplina $\mathrm{O}$ Município e o Habitat nas Metrópoles da América Latina desenvolve anualmente um programa intensivo, de uma semana, com professor de uma metrópole da Região, convidado a apresentar o contexto institucional e as Políticas Públicas desenvolvidas em sua cidade, contribuindo assim, na formação de um acervo de conhecimentos, de textos e de documentos, a cada ano de uma cidade - Rosário, 2003; Buenos Aires, 2004; Bogotá, 2005.

A pesquisa "Reparação de Danos e Ajustamento de Conduta em Matéria Urbanística”, desenvolvida em parceria entre o Laboratório de Habitação e Assentamentos Humanos da Faculdade de Arquitetura e Urbanismo da USP e o Ministério Público - Promotorias de Habitação e Urbanismo de São Paulo, que trabalhou o tema dos assentamentos populares irregulares existentes em áreas de proteção de mananciais na Região Metropolitana de São Paulo.

Partindo desses referenciais, vai-se buscando, com algumas bases comuns, observar as metrópoles latino-americanas procurando compreender similitudes e diferenças, construir identidades e formular padrões urbano-ambientais mais pertinentes, bem como buscar condições mais favoráveis de desenvolvimento.

O texto apresenta o início de um trabalho de Identificação e comparação da manifestação, em algumas metrópoles latino-americanas, de processos que, nas últimas décadas, vêm ocorrendo simultaneamente, ainda que vinculados a origens e razões diversas. São os processos de: Globalização e Reestruturação Econômica, Democratização e Descentralização Político-Administrativa implementadas a partir do término de regimes militares autoritários, Desregulamentação e Informalidade. Visualizam-se nos diferentes países latino-americanos similitudes e simultaneidade na ocorrência desses processos e de seus respectivos impactos e também quanto aos procedimentos assumidos, particularmente na esfera local - municipal e metropolitana. Interessa refletir sobre uma identidade metroplitana latino-americana e uma maneira mais própria de tratar essas cidades. 


\section{Referências Bibliográficas}

ARCE, Luis Fuente; JONQUERA, Carlos Sierralta. Santiago de Chile, ejemplo de una reestructuración capitalista global? Rio de Janeiro: Red Iberoamericana de Investigadores sobre Globalización y Território, 2004.

CUERVO, Luis Mauricio. Globalización y dinámica metropolitana. El caso de Bogotá en los ańos 1990. Camaguey: Red Iberoamericana de Investigadores sobre Globalización y Território, 2002.

CLICHEVSKY, Nora. Pobreza urbana y politicas publicas: entre el desalojo y la regularización. Rosario: Red Iberoamericana de Investigadores sobre Globalización y Território, 2001.

DUCCI, María Elena. Las batallas urbanas de principios del tercer milenio. Rosario: Red Iberoamericana de Investigadores sobre Globalización y Território, 2001.

HARVEY, David. A condição pós-moderna. São Paulo: Loyola, 1992.

KOPPMAN, Sonia Vidal. Transformaciones socioterritoriales de la región metropolitana de Buenos Aires en la última década del siglo XX: la incidencia de las urbanizaciones privadas en la fragmentación de la periferia. Rio de Janeiro: Red Iberoamericana de Investigadores sobre Globalización y Território, 2004.

LOMBARDI, Mario; BERVEJILLO, Federico. Globalización, integración y expansión metropolitana en Montevideo. Hacia una región urbana de la Costa Sur. Toluca: Red Iberoamericana de Investigadores sobre Globalización y Território, 1999.

LOMBARDO, Juan et al. La conformación del espacio urbano en un pais de economía emergente: el caso de cinco municipios en la Región Metropolitana de Buenos Aires. Camaguey: Red Iberoamericana de Investigadores sobre Globalización y Território, 2002.

MARTINS, Maria Lúcia Refinetti. Moradia social e meio ambiente - desafio para o desenvolvimento nas metrópoles latino-americanas. Camaguey: Red Iberoamericana de Investigadores sobre Globalización y Território, 2002. 
MARTINS, Maria Lúcia Refinetti. São Paulo - entre o patrimonialismo e o processo de reestruturação. Toluca: Red Iberoamericana de Investigadores sobre Globalización y Território, 1999.

MATTOS, Carlos de. Reestructuración del mercado metropolitano de trabajo y desigualdades sociales en el Gran Santiago: ‘hacia una ciudad dual? Rosario: Red Iberoamericana de Investigadores sobre Globalización y Território, 2001 .

MATTOS, Carlos de. Redes, nodos y ciudades: transformación de la metrópoli latinoamericana. Camaguey: Red Iberoamericana de Investigadores sobre Globalización y Território, 2002.

NICOLAS, Daniel Hiernaux. Los frutos amargos de la globalización: expansión y reestructuración metropolitana de la ciudad de México. Toluca: Red Iberoamericana de Investigadores sobre Globalización y Território, 1999.

PARNREITER, Christof et al. Convergencia y divergencia del desarrollo metropolitano y globalización en la Ciudad de México y Santiago de Chile. Camaguey: Red Iberoamericana de Investigadores sobre Globalización y Território, 2002.

PÍREZ, Pedro. Buenos Aires: gobernabilidad urbana en una ciudad metropolitana fragmentada., Rosário: Red Iberoamericana de Investigadores sobre Globalización y Território, 2001.

RIBEIRO, Ana Clara Torres. Desigualdade, trabalho e organização social no Rio de Janeiro. Toluca: Red Iberoamericana de Investigadores sobre Globalización y Território, 1999.

SANTOS, Milton. Guerra dos lugares. Folha de São Paulo, São Paulo, 8 ago. 1999. Mais! p. 5-3.

VILLAÇA, Flávio. Espaço intra-urbano no Brasil. São Paulo: Estúdio Nobel, 1998.

VILLAREAL, Diana. Globalización y expansión metropolitana: los casos de las zonas metropolitanas de Ciudad de México y de Monterrey - 1988-1998. Rio de Janeiro: Red Iberoamericana de Investigadores sobre Globalización y Território, 2004. 
